\title{
Klimakamp er helsearbeid
}

\author{
Fortsatt mangler effektive tiltak som kan hindre klimaendringer med meget alvorlige konsekvenser for liv \\ og helse. Forebyggende tiltak vil kreve en snuoperasjon i samfunnsutvikling og livsstil slik at forbruk av \\ fossilt brennstoff raskt reduseres. Helsearbeidere har et særlig ansvar for å bidra til dette.
}

Gunnar Kvåle

gunnar.kvale@cih.uib.no

Ifølge FNs klimapanels femte rapport, publisert i september 2013, peker dagens utvikling mot en global oppvarming som langt overskrider $2{ }^{\circ} \mathrm{C}$. Dette vil få meget alvorlige følger for helse og miljø (1). USA opplevde i fjor den verste tørkesommeren i manns minne. Sommeren 2012-13 i Australia var den varmeste registrert siden målingene startet (2). Tyfonen som traff Filippinene i november 2013 er den sterkeste stormen som er registrert over land noensinne (3).

\section{Tørke og hungersnød}

Klimaendringene er beskrevet som den største trusselen mot global helse i vårt hundreår (4). Klimamodeller viser at ved slutten av hundreåret kan vi forvente alvorlig tørke i Sør-Europa og store deler av Afrika, Midtøsten, Sentral- og Sørøst-Asia og Australia samt Nord- og Sør-Amerika (5). Samtidig er det beregnet at temperaturøkningen blir så stor at langt de fleste somrer ved slutten av hundreåret vil være varmere enn den varmeste sommeren i årene 1900-2006 (6).

Allerede nå rammes nesten en milliard mennesker av alvorlig sult hvert år (7). Med økende tørke og avlingssvikt vil det bli svært mye vanskeligere å mette verdens befolkning, som er forventet å stige til 9-10 milliarder innen 2050. I 2008 opplevde vi at fattige grupper i mange land, blant annet på Haiti, i Egypt og Bangladesh, tok til gatene i opprør mot svikt i mattilførsel og økende matvarepriser (8).

\section{Klimaflyktninger}

Tørke, flom og havstigning fører til at stadig større områder blir ubeboelige. Økende smelting av innlandsis på Grønland og i Antarktis og varmere hav kan gi en gjennomsnittlig havstigning på over en halv meter i løpet av vårt hundreår (1), over tid atskillig mer. Lavtliggende øyer og kystnære områder blir i økende grad utsatt for flom og satt under vann. Ved en havstigning på $40 \mathrm{~cm}$ er det beregnet at antall flomutsatte i Sør- og Øst-Asia vil øke til 94 millioner (9). Innen 2050 kan vi få 150 millioner klimaflyktninger (10). En migrasjon av denne størrelsesorden vil medføre helseproblemer som forsterkes av en allerede sviktende matsikkerhet og vansker med tilgang på ferskvann. Dette vil kunne øke konfliktnivået og bidra til sosial uro og væpnet opprør.

Ekstrem hete er i seg selv et stort helseproblem. Hetebølgen over Europa i 2003 bidro til rundt 70000 flere dødsfall enn i en normalsommer (11). Den ekstremt varme sommeren i Russland i 2010 medvirket til over 50000 dødsfall på grunn av hete og «smog» (12).

\section{Hva må til \\ for å begrense klimaskadene?}

Siden FNs klimamøte i København i 2009 har det vært internasjonal enighet om at den globale temperaturøkningen må begrenses til maksimum to grader over førindustrielt nivå. Det er avgjørende viktig å unngå større økning (13). Selv to grader vil gi meget alvorlige skader. Dette betyr at utslippene fra 2015 må reduseres med over $5 \%$ per år (14). Utslippene globalt har de siste årene økt med $2-3 \%$ i året (15). For å ha en rimelig sjanse til å begrense temperaturstigningen til maksimum to grader, må om lag $80 \%$ av verdens kjente kilder til fossilt brennstoff som fossilindustrien planlegger å utvinne, forbli uutnyttet (16).

Det er fortsatt mulig, men meget krevende, å begrense den globale oppvarmingen til mindre enn $2{ }^{\circ} \mathrm{C}$ (17). Fossilbasert forbruksvekst må snus til en klimanøytral bærekraftig utvikling i alle deler av verden. Jo lenger nødvendige kutt i utslippene utsettes, desto vanskeligere blir det og desto mer alvorlige blir konsekvensene for helse, miljø og økonomi. Parallelt med en rask reduksjon i produksjon og bruk av kull, olje og gass er en gigantisk satsing på energisparing og produksjon av fornybar energi (sol, vann og vind) nødvendig. For å fremme overgangen til fornybarsamfunnet, må store subsidier som fossilindustrien i dag nyter godt av, snarest fases ut, og subsidier til fornybar energi trappes opp.

\section{Ny strategi nødvendig}

De internasjonale klimakonferansene i regi av FN har vist at en global avtale om utslippskutt som monner er vanskelig å få på plass. Om en klimaavtale skulle bli vedtatt i 2015, slik målsetningen er, skal den etter planen tre i kraft først fra 2020. Om vi ikke oppnår kutt i de globale utslipp før dette, vil målet om å begrense oppvarmingen til maksimum $2{ }^{\circ} \mathrm{C}$ vanskelig kunne nås.

En ny og mer ambisiøs strategi er derfor nødvendig. Vi vet at det meste av våre fossile reserver ikke kan utvinnes. En logisk konsekvens vil da være å innføre begrensninger i selskapers rett til utvinning og en global avgift på utvinning som er så høy at den fører til at energi fra fornybare kilder vil bli foretrukket. Den anerkjente klimaforskeren James Hansen har foreslått et system for en gradvis økende avgift som innkreves fra produsenter og importører av fossilt brennstoff (18) og der overskuddet tilbakebetales befolkningen. Ordningen er innført med godt resultat i Britisk Columbia i Canada (19).

Bill McKibben, vinner av Sofieprisen i 2013, har påpekt at vi har en økonomisk «fossilboble» fordi rundt $80 \%$ av fossile reserver som industrien har kartlagt og regnet inn i sin aksjeverdi, må bli værende i grunnen for å kunne unngå meget alvorlige

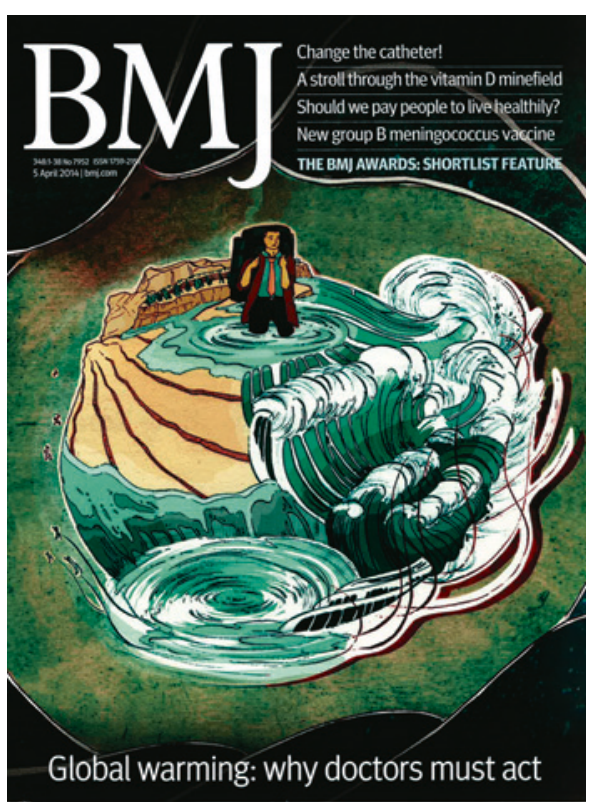

Faksimile fra BMJs aprilnummer som omhandlet klimaendringer 


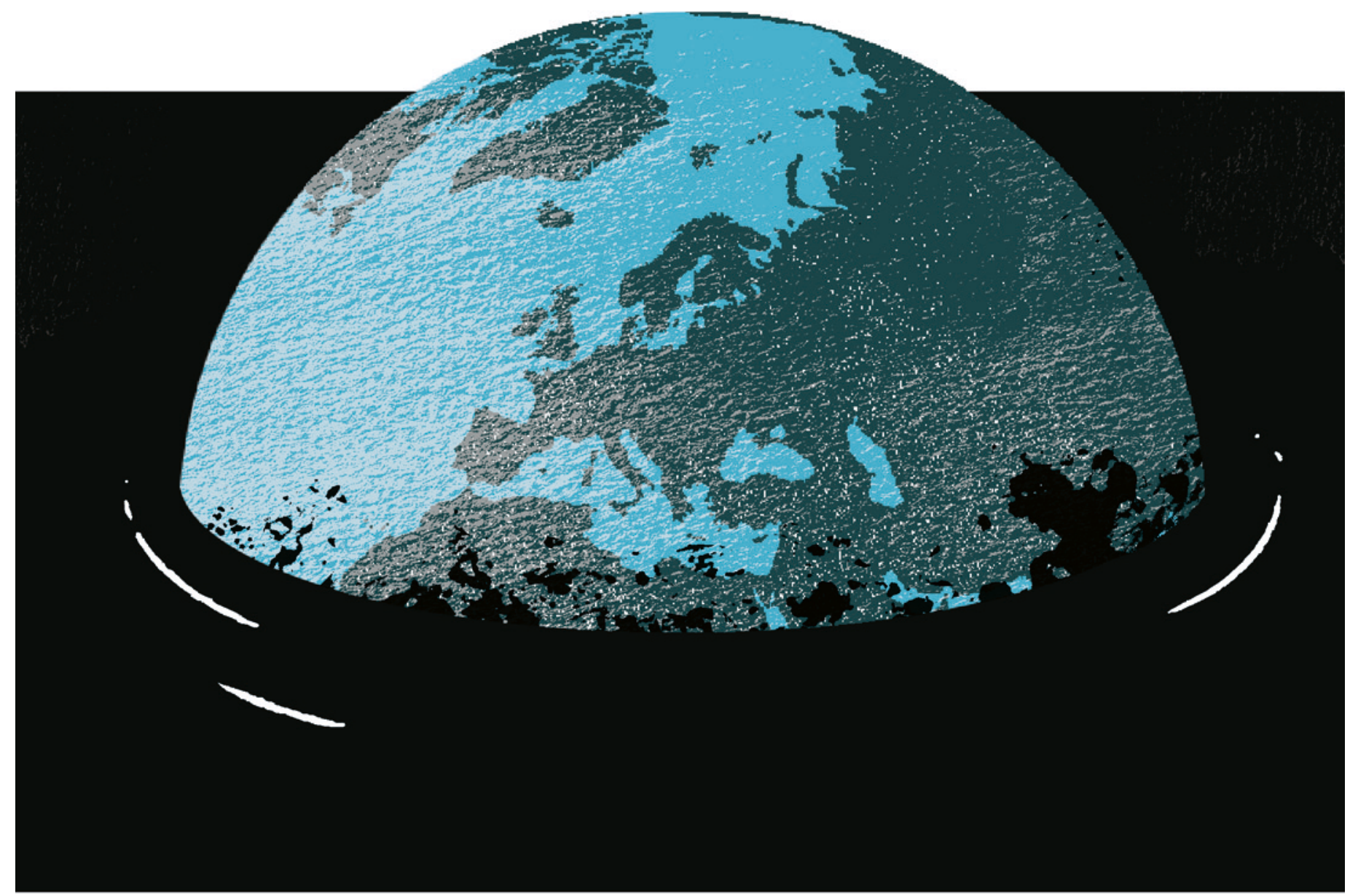

Illustrasjon @ Superpop

klimaskader (16). McKibben har startet en «fossilfri kampanje» som peker på at det ikke bare er etisk problematisk, men også økonomisk risikabelt å investere i kull, olje og gass. Mange investorer, også i Norge, har besluttet å trekke ut sine investeringer fra fossil industri. I en tale til World Economic Forum i januar 2014 anbefalte også direktøren i Verdensbanken at både offentlige og private investorer bør vurdere å trekke ut investeringer fra både kull, olje og gass (20).

\section{Hva kan Norge gjøre?}

Som et rikt oljeproduserende land med god tilgang til fornybar energi er Norge i en unik posisjon til å gå i front mot et nødvendig skifte fra et samfunn basert på fossil energi til et bærekraftig fornybarsamfunn.

Erna Solberg burde lære av Tysklands «Energiwende» som har som mål å redusere klimagassutslippene med 80-95\% innen 2050 ved hjelp av målrettet satsing på energisparing og fornybar energi (21). Fra 1999 har dette resultert $i$ en mer enn firedobling av fornybarandelen i energiproduksjonen.

Fossilindustrien motarbeider nødvendig endring ved fortsatt å satse på uforsvarlig høy utvinning og bruk av fossilt brennstoff. Statoil er intet unntak. I rapporten Energy Perspectives - 2013 beskrives markedsutsiktene for fossile brennstoff basert på at vi skal få en vekst i utslipp som først avtar vesentlig etter 2040 (22). Statoil nevner ikke at dette vil gi en global temperaturøkning på $3-4{ }^{\circ} \mathrm{C}$ med en global klimakrise som resultat.

\section{Helseprofesjonenes rolle}

Det er primært et politisk ansvar å snu utviklingen, men ledende intellektuelle innen kultur og åndsliv, religiøse grupperinger og akademikere fra ulike fagområder har et stort ansvar for å bidra til dette.

Leger og andre helsearbeidere med ansvar for å forebygge helseskade har en spesielt viktig rolle å spille. Som Richard Horton og medarbeidere nylig skrev i en leder i Lancet: «We need a new vision of cooperative and democratic action at all levels of society and a new principle of planetism and wellbeing for every person on this Earth»... «The voice of public health and medicine as the independent conscience of planetary health has a special part to play in achieving this vision»
(23). Også BMJ tar saken opp på lederplass: «This is an emergency. Immediate and transformative action is needed at every level: individual, local, and national; personal, political, and financial» (24). På samme måten som i kampen mot tobakkskader bør helseprofesjonene være i fremste rekke $i$ kampen for nødvendig forebygging av helseskader som skyldes klimaendringer. Slik er vi med på å skape en folkebevegelse som grunnlag for politisk støtte til nødvendig satsing på omlegging til fornybarsamfunnet.

\section{Et moralsk spørsmål}

Klimaendringene representerer en av de største moralske utfordringene verden noen gang har stått overfor. I motsetning til tobakksrøyking rammer overforbruk av fossile brennstoff primært andre som ikke har skyld i situasjonen rike land har ført verden ut i. Om vi mislykkes med en rask og betydelig reduksjon av fossilbasert forbruk, vil skadene bli atskillig mer alvorlige enn hva tobakksrøyking gjennom tidene har forårsaket.

Vi har både som enkeltpersoner og samfunn et etisk ansvar for å redusere klima- 
gassutslippene, ut fra det enkle moralske prinsipp om ikke å skade andre.

På Kirkens hjemmeside står det blant annet: «Når vi skal velge en bærekraftig utviklingsvei fremover, må vi handle slik at andre kan handle på samme måte som oss. Ellers har vi ikke vist at vi forstår klimaspørsmålets moralske karakter» (25).

Dette er et krevende utsagn. Arbeid for en klimavennlig samfunnsutvikling og individuelle tiltak må gå hånd $\mathrm{i}$ hånd. Stadig flere grupper av engasjerte enkeltindivider arbeider for snuoperasjonen som er nødvendig, både i Norge og internasjonalt (26).

\section{Gunnar Kvåle (f. 1942)}

er professor emeritus ved Senter for internasjonal helse, Universitetet i Bergen og medlem av koordinatorgruppen for Norsk nettverk for klima og helse.

Forfatter har fylt ut ICMJE-skjemaet og oppgir ingen interessekonflikter.

\section{Litteratur}

1. Intergovernmental Panel on Climate Change. Summary for policymakers. I: Stocker TF, Qin D, Plattner G-K et al, red. Climate change 2013: The physical science basis. Cambridge: Cambridge University Press, 2013.

2. Australian Government Bureau of Meteorology. www.bom.gov.au/climate/updates/ summer-heatwave-2013.shtml (10.4.2014).

3. Fischetti M. Was Typhoon Haiyan a record storm? Scientific American 12.11.2013. http://blogs.scientificamerican.com/observations/ 2013/11/12/was-typhoon-haiyan-a-record-storm/ (10.4.2014)

4. Costello A, Abbas M, Allen A et al. Managing the health effects of climate change. Lancet 2009; 373 1693-733.

5. Day A. Drought under global warming: A review. Wiley Interdisciplinary Reviews. Climate Change 2011; 2: 45-65. http://onlinelibrary.wiley.com/doi/ 10.1002/wcc.81/abstract (10.4.2014).

6. Battisti DS, Naylor RL. Historical warnings of future food insecurity with unprecedented seasonal heat. Science 2009; 323: 240-4

7. Food and Agriculture Organization of the United Nations. The state of food insecurity in the world Roma: Food and Agriculture Organization of the United Nations, 2012

8. Riots, instability spread as food prices skyrocket. CNN 14.4.2008. http://edition.cnn.com/2008/ WORLD/americas/04/14/world.food.crisis/ (10.4.2014).

9. Cruz RV, Harasawa H, Lal S et al. Asia. I: Parry ML Canziani OF, Palutikof JP et al, red. Climate change: Impacts, adaptation and vulnerability. Cambridge: Cambridge University Press, 2007: 484.

10. World Watch Institute. Climate refugees. A human cost of global warming. World Watch Institute, 2014. www.worldwatch.org/climate-refugeeshuman-cost-global-warming (10.4.2014].

11. Robine J-M, Cheung SLK, Le Roy S et al. Death toll exceeded 70,000 in Europe during the summer of 2003. Comptes Rendus Biologies 2008; 331: 171-8. www.sciencedirect.com/science/article/pii/ S1631069107003770 (10.4.2014).

12. Parry W. Recent heat waves likely warmest since 1500 in Europe. LiveScience 17.3.2011. www.livescience.com/13296-european-russiaheat-waves-climate-change.html (10.4.2014).

13. World Bank. Turn down the heat. Why a 4 degrees $\mathrm{C}$ warmer world must be avoided. Washington: The World Bank, 2013

14. German advisory panel on climate change (WBGU). Solving the climate dilemma. The budget approach www.mng.org.uk/gh/private/ wbgu_sn2009_en.pdf (10.4.2014).
15. 2013 Global Carbon Project. http://cdiac.ornl.gov/ GCP/carbonbudget/2013/ (8.4.2014)

16. McKibben B. Global warming's terrifying new math. Rolling stones 19.7.2012. www.rollingstone. $\mathrm{com} /$ politics/news/global-warmings-terrifying new-math-20120719 (10.4.2014)

17. International Energy Agency. Redrawing the energy-climate map. Paris: International Energy Agency, 2013

18. Wikipedia. Fee and dividend. http://en.wikipedia. org/wiki/Fee and dividend 111.4 .2014

19. Elgie S, McClay J. Policy Commentary/Commentaire BC's Carbon Tax Shift Is Working Well after Four Years (Attention Ottawa). Can Public Policy 2013; 39: 1-10.

20. World Bank chief backs fossil fuel divestment drive. RTTC 27.1.2014. www.rtcc.org/2014/01/27/ world-bank-chief-backs-fossil-fuel-divestmentdrive/ (11.4.2014)

21. Wikipedia. Energy transition in Germany. http://en wikipedia org/wiki/

Energy_transition_in_Germany (10.4.2014).

22. Statoil. Energy perspectives. Long-term macro and market outlook. Oslo: Statoil, 2013.

23. Horton R, Beaglehole R, Bonita R et al. From public to planetary health: a manifesto. Lancet 2014; 383: 847

24. McCoy D, Montgomery H, Arulkumaran S et al. Climate change and human survival. BMJ 2014 348: g2351.

25. Den norske kirke. Økende miljøengasjement www. kirken.no/?event=doLink\&famID=12007 (11.4.2014).

26. Klimavalg 2013. Ny klimaallianse på veg http://klimavalg2013.no/ (11.4.2014)

Mottatt 4.2. 2014, første revisjon innsendt 11.4. 2014, godkjent 14.5. 2014. Redaktør: Kari Tveito. 